\title{
EDITORIALS
}

\section{Biospheric Stability and the Stratosphere}

Although the stratosphere can scarcely be regarded as part of the biosphere, it is quite vitally important to biospheric stability. Consequently it is a source of profound relief that continuing efforts in a few remaining quarters to develop large numbers of supersonic transport aircraft (SSTs) have run into so many problems that they seem bound to fail. Indeed it has long been the conviction of many of us that it would be sheer folly of the most dangerous kind to continue with uncontrolled multiplication of Tupolev, Concorde, or any other SSTs, before it has been scientifically demonstrated that their use would not lead to a serious reduction of the ozone in the stratosphere-remote though this may seem. It is also a relief to note that the threat to stratospheric ozone posed by the chlorine-containing fluorocarbons (fluorochlorohydrocarbons or 'freons') used as aerosol propellants and in refrigeration and air-conditioning, is now becoming so widely recognized that their production may soon cease. Thus it was high time for the establishment recently of a U.S. Federal Interagency Task-force on Inadvertent Modification of the Stratosphere, while the reputedly largest-by-far manufacturer of these substances has undertaken, 'If . . creditable scientific data show that any fluorocarbons cannot be used without a threat to health, [to] stop production of the products in question' (Du Pont Management Bulletin, 4(1), p. 4, February 1975).

This refers to human health; but what of the other biota on which Man, though generally the world's pandominant, is dependent for the wherewithal of life? To a remarkable extent it has been the ozone 'shield' in the stratosphere that has allowed life to develop on Earth, and enabled plants and animals to evolve and flourish. For the ozone absorbs in its own formation, before they can reach the surface of the Earth, most of the ultraviolet rays emanating from the sun. These rays are lethal to many microorganisms, which in evolution must have preceded more complex organisms-including, ultimately, Man, who is himself adversely affected by certain wavelengths of ultraviolet radiation, which, for example, are authoritatively reported to accelerate ageing and increase the incidence of skin cancer. Indeed it seems quite likely that, were it not for the ozone shield, life on Earth would not have evolved, at least in anything like its present vast range of forms, while drastic reduction of the ozone shield could conceivably jeopardize life on Earth. Consequently any threat to the ozone shield should be viewed with the gravest possible concern, and to go on perpetrating the means of its possible destruction would seem to us the height of irresponsible folly pending scientific demonstration that specialists' warnings are unfounded-see, for instance, Professor Harold S. Johnston's 'Pollution of the Stratosphere', published in our Autumn 1974 issue (pp. 163-76). Other threats to the ozone shield include nuclear attacks, which produce large amounts of nitric oxide, and it has been calculated that a major event of this kind could lead to a 50\% reduction in stratospheric ozone (Paul J. Crutzen in Ambio, 3(6), pp. 201-10, 1974).

There are quite numerous ways in which the destruction of ozone is known to be catalyzed by such substances as water vapour and oxides of nitrogen, which are emitted in large amounts by SSTs, and by chlorine which is allegedly released from freons decomposed by ultraviolet radiation in the stratosphere. Moreover, as we pointed out in our Autumn 1974 issue ('Thoughts on Some Conceivable Ecodisasters', Environmental Conservation, Vol. 1, No. 3, pp. 177-89), 'SSTs are apt to fly largely at an altitude not so very far below that of maximum concentration of ozone in the stratosphere!' Surely we should, in such grave and controversial matters, pursue a safety-first policy of 'guilty until proven innocent'-rather than the reverse, as has been suggested most frighteningly in some interested circles.

N. P.

\section{The Turning-point : Towards a New Ideology?}

At the beginning of the year, we all bid each other our traditional 'Happy New Year', but few of us could really believe in a 'bright future'. It seems that we are now living at a major turning-point in the history of our industrial society-the basic premises on which we have built it are being questioned more seriously and more widely than ever before.

Economic development, with its special set of human values, has brought, is still bringing, and will continue to bring, a certain happiness to large numbers of people; but how lasting is this materialistic euphoria? Is it not, with all its implications, undermining the long-term stability of our society? Science-Man's striving to understand the natural forces with which he has evolved-is the cornerstone of modern society; but how much 